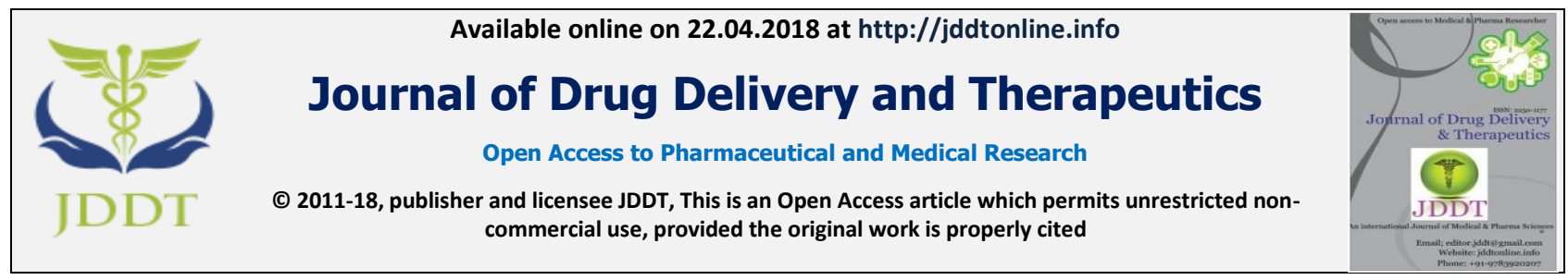

Open - Access

Research Article

\title{
EVALUATION OF A MODIFIED BIOMATERIAL OF TYMPANOTONUS FUSCATA SHELL POWDER II: FORMULATION OF PYRIMETHAMINE AND PYRIDOXINE HYDROCHLORIDE TABLETS
}

\author{
Kenneth C. Ugoeze ${ }^{1 *}$, Amarauche Chukwu ${ }^{2}$ \\ ${ }^{1}$ Department of Pharmaceutics \& Pharmaceutical Technology, Faculty of Pharmaceutical Sciences, University of Port Harcourt, \\ Nigeria \\ ${ }^{2}$ Department of Pharmaceutical Technology and Industrial Pharmacy, Faculty of Pharmaceutical Sciences, University of Nigeria, \\ Nsukka, Nigeria
}

\section{ABSTRACT}

A novel modified biomaterial of periwinkle shell powder, MBPSP was developed from Tympanotonus fuscata. It was assessed as a bulking agent in the formulation of pyrimethamine and pyridoxine hydrochloride tablets adopting dicalcium phosphate dihydrate (DCP) as a standard. A $100 \mathrm{~g}$ of the ground periwinkle shell was broken down in $166.0 \mathrm{ml}$ of $2 \mathrm{M}$ hydrochloric acid, clarified and treated with $5 \mathrm{M}$ sodium hydroxide. The thick white precipitate obtained was washed severally and to it, ortho-phosphoric acid was dropped in bits until a thick, dehydrated bulk was attained which was dried at $60^{\circ} \mathrm{C}$ and classified with $250 \mu \mathrm{m}$ sieve. The product was coded MBPSP. Two batches of granules containing pyrimethamine $(25 \mathrm{mg})$ and pyridoxine hydrochloride $(50 \mathrm{mg})$ were generated by the wet granulation employing MBPSP alongside DCP. The granules were lubricated with magnesium stearate and talc and compacted into tablets at $7.55 \mathrm{kN}$ using a $10.50 \mathrm{~mm}$ diameter die and flat-faced punch fixed in a hydraulic hand press. The tablet produced were evaluated using the British Pharmacopoeia specifications. The weight variation for the pyrimethamine or pyridoxine hydrochloride tablets containing MBPSP or DCP were $0.06,0.1,0.097$ and $0.143 \%$ respectively. The total drug content for the individual lots of tablets for either pyrimethamine or pyridoxine hydrochloride was within $85.00-115.00 \%$ of their label claim. Higher mechanical strength were noted for the batch of tablets manufactured with DCP and containing pyrimethamine and pyridoxine hydrochloride than MBPSP. Though the entire batches of tablets for the two drugs manufactured with either MBPSP or DCP disintegrated in less than 5.00 min with no significant difference in their individual disintegrating time $(p>0.05)$, pyridoxine hydrochloride tablets prepared with DCP disintegrated in lesser time when compared to MBPSP $(\mathrm{p}<0.05)$. Only the pyrimethamine tablets prepared with MBPSP attained $75.00 \%$ drug release in $45.00 \mathrm{~min}$ in line with the United States Pharmacopoeia (USP) criteria. Therefore, MBPSP could be another very useful bulking agent in the formulation of pyrimethamine immediate-release tablets by the wet granulation technique.

Keywords: Modified biomaterial, Tympanotonus fuscata, periwinkle, shell, pyrimethamine, pyridoxine hydrochloride, tablet.

Article Info: Received 08 Feb, 2018; Review Completed 20 April 2018; Accepted 21 April 2018; Available online 22 April 2018

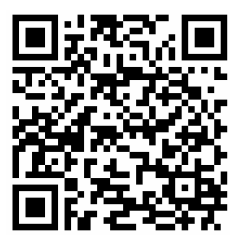

\section{Cite this article as:}

Ugoeze KC, Chukwu A, Evaluation of a modified biomaterial of Tympanotonus fuscata shell powder II: Formulation of pyrimethamine and pyridoxine hydrochloride tablets, Journal of Drug Delivery and Therapeutics. 2018; 8(2):188-193 DOI: http://dx.doi.org/10.22270/jddt.v8i2.1709

Kenneth C. Ugoeze, Department of Pharmaceutics \& Pharmaceutical Technology, Faculty of Pharmaceutical Sciences, University of Port Harcourt, Nigeria

\section{INTRODUCTION}

Administration of drug products through the mouth is often the ideal path for the use of drugs since is a cheap way of drug treatment, simply managed, users easily adapt to the direction for the use of the medicinal product, changes in any drug formulation is easy to adjust to, etc. In the past years, several drug products administered through the mouth have been designed ${ }^{1}$. Tablets are single compact dosage formulae designed to be administered orally. They are prepared from combination of pulverized solid materials encompassing the therapeutically viable substance or the active ingredient (API). It also includes several ingredients which assist in the compression of intact tablet. Tablets 
are usually produced through the process of wet granulation (WG), dry granulation (DG) or direct compression (DC). Any of these methods have its gains and inconveniences ${ }^{2}$. The adoption of any of these processes may actually depend on the nature of the pharmaceutical excipient available for use among other factors around the API.

It has been noted that inactive ingredients are blended in addition to the API in order to enhance the tableting properties as well as its bioavailability. The pharmaceutical excipients may be categorized considering their application in the production of tablet. They comprise diluents, binders, glidants, lubricants, disintegrants, plasticizers, etc. ${ }^{3}$. They influence the stability, bioavailability and the process by which the tablets are prepared. Diluents are usually utilized to enhance the required size of a tablet for effective management. This is the reason they are referred to as bulking agents or fillers ${ }^{4}$. An ideal diluents like other ingredients added in addition to the API, are expected to be chemically and physiologically inactive and should not conflict with the bioavailability of the API. Such excipients are also expected to be easily sourced and affordable and should be easily manipulated to a tablet. Instances of diluents comprise lactose, dry starch, sucrose, mannitol, calcium sulphate, dicalcium phosphate, etc. ${ }^{5}$. Most pharmaceutical inactive ingredients originated from natural materials. They may be generated either chemically or by other means and they have been utilized in the pharmaceutical sector as tablet binders, disintegrants, bulking agents, etc. ${ }^{6,7}$.

Tympanotonus fuscata var Radula (L) is also noted as the periwinkle. It has a protection of shell and is described as a Mollusca which the foremost marine animal possessing an outer frame is termed shell ${ }^{8}$.

In this studies, the milled shell of Tympanotonus fuscata was improved and applied to size-up tablets in the production of pyrimethamine and pyridoxine hydrochloride tablets by the wet granulation procedure. Similar tablets containing dicalcium phosphate dihydrate (DCP) as diluent was formulated. The production and early assessment of the physical and some chemical nature of the biological material of the shell of $T$. fuscata has been recorded ${ }^{9}$. The physicochemical characteristics of the adjusted micronized material derived from the Tympanotonus fuscata shell (MBPSP) in line with possible utilization in the pharmaceutical sector has as well been cited in the literature ${ }^{10}$. Ugoeze and Udeala stated the use of a bioash resultant from the periwinkle shell as a carbon dioxide $\left(\mathrm{CO}_{2}\right)$ donor in the making of an effervescent low dose aspirin tablet ${ }^{11}$.

\section{MATERIALS AND METHODS}

\section{Materials}

The following materials were used and include: hydrochloric acid $(\mathrm{HCl})$, sodium hydroxide $(\mathrm{M} \& \mathrm{~B}$, England), gelatin (Fisher, USA), dicalcium phosphate dihydrate (DCP) (Rousselot, Belgium), corn starch, magnesium stearate, talc, ethanol (BDH, England).
Pyrimethamine and pyridoxine hydrochloride were donated by Juhel Nigeria Ltd.

\section{Methods}

\section{Preparation of modified biomaterial of Tympanotonus fuscata shell powder}

The procedure documented by Ugoeze and Chukwu was adopted $^{10}$. A $100 \mathrm{~g}$ of the micronized shell of Tympanotonus fuscata was broken-down in $166.0 \mathrm{ml}$ of $2 \mathrm{M}$ hydrochloric acid, removing extraneous materials by filtration. The acidic filtrate was neutralized with 5 M sodium hydroxide. The white precipitate obtained was washed severally. Ortho-phosphoric acid was dropped in bits to the profuse aqueous suspension of the mass to achieve a dense, dehydrated mass which was dried to constant weight at $60{ }^{\circ} \mathrm{C}$ in hot air oven (Uniscope, England). The dried mass was classified with a $250 \mu \mathrm{m}$ stainless steel sieve (Retch, Germany). The powder was stored in an amber coloured powder bottle and was referred to in this work as the modified biomaterial of periwinkle shell powder (MBPSP).

\section{Formulation of tablet}

Table 1: Formula for producing pyrimethamine tablet using MBPSP or DCP. Each tablet contains $25 \mathrm{mg}$ of pyrimethamine and weighs $200 \mathrm{mg}$

\begin{tabular}{|l|c|}
\hline Ingredient & Percentage per tablet $(\% \mathrm{w} / \mathrm{w})$ \\
\hline Pyrimethamine & 12.50 \\
\hline Gelatin & 2.00 \\
\hline Corn starch & 10.00 \\
\hline Magnesium stearate & 1.00 \\
\hline Talc & 0.50 \\
\hline MBPSP or DCP & 74.00 \\
\hline
\end{tabular}

Table 2: Formula for the production of pyridoxine hydrochloride tablets using MBPSP or DCP. Each tablet contains $50 \mathrm{mg}$ of pyridoxine hydrochloride and weighs $300 \mathrm{mg}$

\begin{tabular}{|l|c|}
\hline Ingredient & $\begin{array}{c}\text { Percentage per tablet } \\
(\% \mathrm{w} / \mathrm{w})\end{array}$ \\
\hline Pyridoxine hydrochloride & 16.66 \\
\hline Gelatin & 2.00 \\
\hline Corn starch & 10.00 \\
\hline Magnesium stearate & 1.00 \\
\hline Talc & 0.50 \\
\hline MBPSP or DCP & 69.84 \\
\hline
\end{tabular}

\section{Granulation}

Using the formula shown in Tables 1 and 2, granules of pyrimethamine $(25 \mathrm{mg})$ or pyridoxine hydrochloride (50 $\mathrm{mg}$ ) respectively were produced by the wet granulation technique. In each formulation, the API was blended with corn starch and the MBPSP or DCP to attain consistency. A paste of gelatin was made in a little warm water and incorporated into the respective powder blends to wet-mass them. More water was sprinkled and it was kneaded further and granulated through sieve 10 $(1.7 \mathrm{~mm})$. It was dried in a hot air oven at $60{ }^{\circ} \mathrm{C}$. The batches of the dried mass were screened with sieve 16 
$(1.00 \mathrm{~mm})$ and the granules obtained were stored in airtight amber coloured glass containers.

\section{Compression of tablets}

Each batch of the granules containing pyrimethamine or pyridoxine hydrochloride and prepared with MBPSP or DCP was mixed with magnesium stearate and talc respectively and compressed for $30 \mathrm{~s}$ at a compression pressure of $7.35 \mathrm{kN}$ making use of a $10.5 \mathrm{~mm}$ diameter die and flat-faced punches on a hydraulic hand press (Model C, Carver Laboratory Press, Menomonee Falls, WI. USA). All the compressed tablets were left in a desiccator for $24 \mathrm{~h}$ before their properties were evaluated.

\section{Evaluation of tablets}

The respective batches of tablets containing pyrimethamine or pyridoxine hydrochloride and prepared with MBPSP or DCP were evaluated as outlined in the procedures below. A triplicate readings was obtained each time and their mean was computed.

\section{Uniformity of tablet weight}

The weight of twenty tablets from each batch containing pyrimethamine or pyridoxine hydrochloride and produced with either MBPSP or DCP were determined individually on an electronic balance (Mettler, Germany) $)^{12}$.

\section{Uniformity of tablet thickness}

Using a micrometer screw gauge (VIS, Poland), the thickness of each tablet in the respective batches used for uniformity of weight was measured.

\section{Tablet hardness}

The hardness of ten tablets from the batches containing pyrimethamine or pyridoxine hydrochloride and produced with MBPSP or DCP was evaluated ${ }^{12}$ making use of a digital hardness tester (DBK Instruments, England.

\section{Tablet friability}

Using ten tablets from each batch which were dusted, weighed and positioned in a tablet friabilator (Veego Tablet Friability Test Apparatus, India) regulated at 25 revolution per minute (rpm) for $4 \mathrm{~min}$, the friability of each batch was determined.

\section{Tablet disintegration time}

The time for the complete break-down of six tablets from the respective batches containing pyrimethamine or pyridoxine hydrochloride and designed using MBPSP or DCP was estimated in disintegration apparatus (Veego Disintegration Apparatus, India). The instrument consisted of a rigid basket-rack assembly backup of six cylindrical glass tubes. A $1 \mathrm{~L}$ of $0.1 \mathrm{~N}$ hydrochloric acid contained in a glass beaker served as a medium which was kept at $37 \pm 1^{\circ} \mathrm{C}$. Tablet break-down was recorded when no deposit of undissolved tablet persisted on the screen of the test apparatus ${ }^{12}$.

Tablet total drug content
From each batch of pyrimethamine and pyridoxine hydrochloride tablets respectively, ten wholesome tablets were crushed and the mass of powders corresponding to the mean weight of the individual lots was evaluated spectrophotometrically for its intact content of the API.

\section{Tablet tensile strength}

The tensile strength for the respective batches of tablets was calculated from the equation below:

$T=2 P / \pi d t$

\section{Dissolution rate studies}

The dissolution rate studies for pyrimethamine and pyridoxine hydrochloride tablets respectively was considered in a dissolution apparatus 2, the paddle method (Erweka DT 80, Germany), individually operated at the speed of 50 revolutions per minute (rpm) for both pyrimethamine and pyridoxine hydrochloride in $900 \mathrm{ml}$ of $0.1 \mathrm{~N}$ hydrochloric acid kept at $37 \pm 1^{\circ} \mathrm{C}^{12}$. In each case, a $5.0 \mathrm{ml}$ of sample was taken out of the medium at the time intervals between 5.0- $45.0 \mathrm{~min}$, changing same with $5.0 \mathrm{ml}$ of plain $0.1 \mathrm{~N}$ hydrochloric acid solution each time. The absorption of the dissolved solutions of the APIs was read in a Spectrophotometer 160-A (Japan) at 253 and $290 \mathrm{~nm}$ for pyrimethamine and pyridoxine hydrochloride respectively.

\section{Statistical analysis}

All statistical analysis of data involving the Independent T-Test was carried out using the IBM SPSS Statistics 20 software.

\section{RESULTS AND DISCUSSIONS}

\section{Physical properties of tablets}

The properties of the pyrimethamine or pyridoxine hydrochloride tablets prepared with MBPSP or DCP are shown in Tables 3 and 4 respectively.

\section{Appearance of tablets}

The tablets of both drugs with MBPSP or DCP were glossy. There was no discolouration.

\section{Tablet weight uniformity and thickness}

The weight variation for the pyrimethamine or pyridoxine hydrochloride tablets containing MBPSP or DCP was $0.06,0.1,0.097$ and $0.143 \%$ respectively. The British Pharmacopoeia (12) specified up to $7.5 \%$ for weight variation for tablets weighing 130-324 mg. The results of the weight variation were low and may be due evenness in the flowability of granules during the tableting. Statistical analysis showed that there was no major variances in the weights of tablets in the individual lots of the pyrimethamine and pyridoxine hydrochloride produced with MBPSP or DCP ( $p>0.05)$. A comparable result was similarly obtained for respective tablet thickness for pyrimethamine and pyridoxine hydrochloride for the two bulking agents examined. 
Table 3: Properties of pyrimethamine tablet prepared with MBPSP or DCP

\begin{tabular}{|l|c|c|c|}
\hline Tablet parameter & MBPSP & DCP & P value \\
\hline Uniformity of weight $(\mathrm{mg})$ & $199.89 \pm 0.37$ & $200.20 \pm 0.56$ & $\mathrm{P}>0.05$ \\
\hline Thickness (mm) & $1.80 \pm 0.12$ & $1.54 \pm 0.13$ & $\mathrm{P}<0.05$ \\
\hline Drug Content (\%) & $25.56 \pm 0.5$ & $25.62 \pm 0.65$ & $\mathrm{P}<0.05$ \\
\hline Disintegration time (min) & $2.20 \pm 0.26$ & $2.00 \pm 0.26$ & $\mathrm{P}>0.05$ \\
\hline Hardness (N) & $77.19 \pm 0.47$ & $81.18 \pm 0.22$ & $\mathrm{P}<0.05$ \\
\hline Friability (\%) & $0.90 \pm 0.01$ & $0.84 \pm 0.01$ & $\mathrm{P}<0.05$ \\
\hline Tensile strength $\left(\mathrm{mN} / \mathrm{m}^{2}\right)$ & $3396.75 \pm 0.24$ & $3576.80 \pm 0.56$ & $\mathrm{P}<0.05$ \\
\hline HFR $^{*}$ & $86.25 \pm 0.35$ & $93.45 \pm 0.48$ & $\mathrm{P}<0.05$ \\
\hline
\end{tabular}

Table 4: Properties of pyridoxine hydrochloride tablet prepared with MBPSP or DCP

\begin{tabular}{|l|c|c|c|}
\hline Tablet parameter & MBPSP & DCP & P value \\
\hline Uniformity of weight (mg) & $300.29 \pm 0.61$ & $300.43 \pm 1.40$ & $\mathrm{P}>0.05$ \\
\hline Thickness (mm) & $1.80 \pm 0.01$ & $1.51 \pm 0.03$ & $\mathrm{P}<0.05$ \\
\hline Drug Content (\%) & $51.76 \pm 0.87$ & $50.92 \pm 1.05$ & $\mathrm{P}>0.05$ \\
\hline Disintegration time (min) & $3.95 \pm 0.07$ & $2.37 \pm 0.32$ & $\mathrm{P}<0.05$ \\
\hline Hardness (N) & $168.01 \pm 0.22$ & $101.03 \pm 0.16$ & $\mathrm{P}<0.05$ \\
\hline Friability $(\%)$ & $0.79 \pm 0.01$ & $0.95 \pm 0.63$ & $\mathrm{P}<0.05$ \\
\hline Tensile strength $\left(\mathrm{mN} / \mathrm{m}^{2}\right)$ & $5656.34 \pm 0.43$ & $3983.26 \pm 0.45$ & $\mathrm{P}<0.05$ \\
\hline HFR $^{*}$ & $216.98 \pm 0.19$ & $106.18 \pm 0.18$ & $\mathrm{P}<0.05$ \\
\hline
\end{tabular}

*Hardness Friability Ratio

\section{Total drug content}

The results of the total drug content for pyrimethamine and pyridoxine hydrochloride containing MBPSP or DCP were $102.24,102.48,103.52$ and $101.84 \%$. None was lower than $85 \%$ or above $115 \%$. The British Pharmacopoeia ${ }^{12}$ specified that a preparation complies with the test for total drug content if each individual content is between $85.00 \%$ and $115.00 \%$ of the average content. There was no significant variation in the values for MBPSP and DCP ( $>>0.05)$.

\section{Tablet mechanical strength}

A tablet hardness of $4.00 \mathrm{~kg}(\approx 39.00 \mathrm{~N})$ is commonly the minimum for acceptable tablets ${ }^{13}$. Tablets administered by mouth usually possess a hardness of $4.00-10.00 \mathrm{~kg}(\approx 39.00-98.00 \mathrm{~N})$. Tablet hardness mainly increase in value with consistent storing of tablets and is affected by the shape, chemical properties, binding agent and the compacting pressure used to prepare the tablet ${ }^{14,15}$.

The friability test is strictly interconnected to tablet hardness and is intended to assess the capability of the tablet to stand abrasions in container during transportation. A friability of less than $1.00 \%$ is assessed as acceptable particularly for tablets manufactured by wet granulation. However, tablets made by direct compaction could result to friability above unity ${ }^{16}$.

The tensile strength is an additional factor utilized to evaluate the strength of tablets in withstanding wear and tear. It is a degree of the bonding power of a tablet ${ }^{17}$.

The grouping of the tablet hardness and friability, a word chosen as the hardness-friability ratio (HFR) which is one more estimation of the mechanical strength of pharmaceutical tablets ${ }^{14,15,18}$. The hardness offers an estimation of tablet mechanical strength while the friability provides the degree of the tablet softness. Investigations have revealed that the greater the HFR values, the stronger the tablet ${ }^{14,15}$. In terms of tablet mechanical strength, it was generally recorded that higher values of mechanical strength were noted for tablets containing DCP in both pyrimethamine and pyridoxine hydrochloride than MBPSP. This trend was consistent from the results obtained for friabilty, tensile strength and hardness-friability-ratio (HFR) $(\mathrm{p}<0.05)$.

\section{Disintegration time}

For a good number of plain tablets, the British Pharmacopoeia call for tablets crumbling within $15 \mathrm{~min}$ when in contact with water even though the value may be different for other types of uncoated tablets. For tablets that are coated, up to 2 hours may be needed for complete crumbling of a tablet when in contact with a fluid $^{12,19-21}$.

The entire batches of tablets containing either pyrimethamine or pyridoxine hydrochloride, manufactured with either MBPSP or DCP disintegrated in less than $5 \mathrm{~min}$. However, for pyrimethamine tablets, there was no significant difference in the disintegrating time between tablets containing either MBPSP or DCP ( $>0.05)$. Meanwhile, for pyridoxine tablets, those prepared with DCP had lower disintegration timing when compared to MBPSP ( $\mathrm{p}<0.05)$.

\section{Drug dissolution}

The dissolution rate profiles for pyrimethamine and pyridoxine hydrochloride tablets made with either MBPSP or DCP are displayed in Figures 1 and 2 respectively. The United States Pharmacopoeia (USP) ${ }^{22}$ specified that not less than $75.00 \%$ of the stated quantity of pyrimethamine ought to be dissolved in $45.00 \mathrm{~min}$. For pyridoxine hydrochloride tablet, the USP also stated that not less than $75.00 \%$ of the noted amount should be released in solution in $45.00 \mathrm{~min}$. 


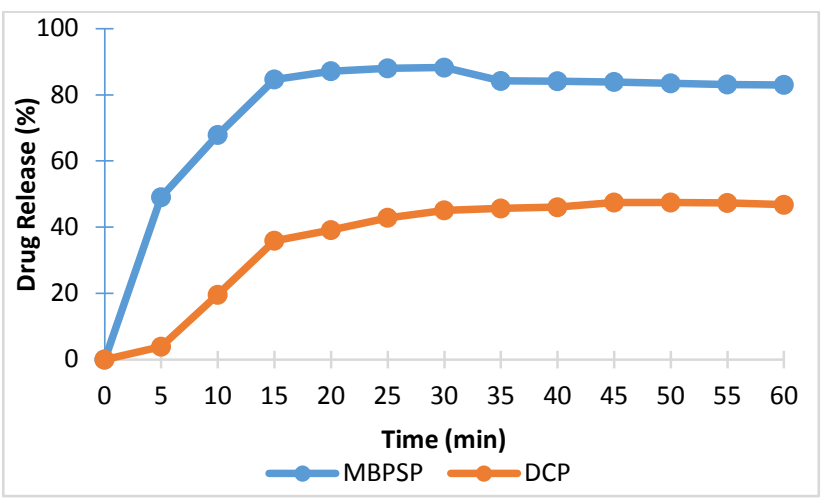

Figure 1: Dissolution rate profile for pyrimethamine tablets prepared with MBPSP or DCP in $0.1 \mathrm{~N} \mathrm{HCl}$ at $37 \pm 1^{\circ} \mathrm{C}$

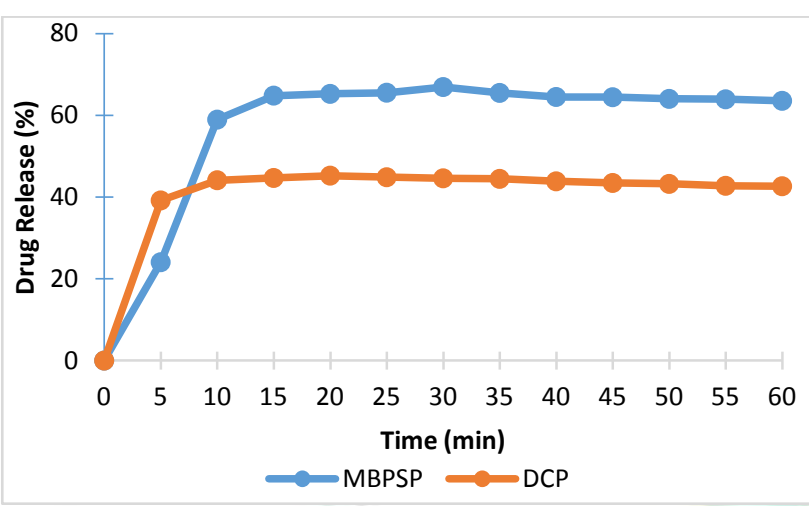

Figure 2: Dissolution rate profile for the pyridoxine hydrochloride tablets formulated with MBPSP or DCP in $0.1 \mathrm{~N} \mathrm{HCl}$ at $37 \pm 1^{\circ} \mathrm{C}$

Considering Figure 1, maximal amount $(88.00 \%)$ of pyrimethamine was released at $25.00 \mathrm{~min}$ from MBPSP.

\section{REFERENCES}

1. Iannucelli V, Coppi G, Bernabei MT, Camerorni R, Air compartment multiple-unit system for prolonged gastric residence. Part-I: Formulation study. Int J Pharm., 1998; 174:47-54.

2. Avachat A and Ahire V. Characterization and evaluation of spray dried co- processed excipients and their application in solid dosage forms. Indian J Pharm Sci, 2007; 69:85-90.

3. Liebermam H.A. and Lachman L. "Tablets": in Pharmaceutical Dosage Forms, Vol.1, Marcel Dekker Inc.; New York, 1980.

4. Carr, R.L. "Evaluating flow properties of solids", Chem. Eng., 1965; 72:163 - 168 .

5. Lachman L.; Lieberman H.A. \& Kanig J.L. "Sustained Release Formulations', in: Theory and Practice of Industrial Pharmacy, 3rd ed.; Lea and Febiger, Philadelphia, 1986.

6. WHO. Training Workshop on Pharmaceutical Development with a Focus on Paediatric Medicines. 15-19 October 2007. Available from: http://studylib.net/doc/9264523/guidelines--world-health-organization. Retrieved on 22nd June 2017.

7. Wade A, Weller PJ. Handbook of Pharmaceutical Excipients. 11th Ed. The Pharmaceutical Press: London, 1994; 426-8.

8. Edmund J. "Sea shells \& other mollusc found on West African shores \& estuaries". In: Descriptive manual of Janet Edmund. Ghana University press, Accra, 1978; 20:100-101.

9. Ugoeze K.C, Chukwu A. Preliminary Evaluation of the Properties of Biomaterial of Tympanotonus fuscata shell as Pharmaceutical Excipient. Int. Res. J. Pharm. 2015; 6(2):104107.

10. Ugoeze K.C, Chukwu A. Physico-chemical Properties of a Modified Biomaterial from Tympanotonus Fuscata (Periwinkle) Shell Powder Considered as Pharmaceutical
Not up to $75.00 \%$ of the same drug could be dissolved after $45.00 \mathrm{~min}$. Figure 2 depicts that neither MBPSP nor DCP could release up to $75.00 \%$ of pyridoxine hydrochloride from the tablets formulated with either, though, the rate of release of pyridoxine hydrochloride was higher in MBPSP. These results suggest that the formulation of pyrimethamine employing MBPSP complied with the USP requirements for its drug release. Neither MBPSP nor DCP was suitable for pyridoxine hydrochloride tablets.

\section{CONCLUSION}

A novel inert material applicable as a tablet bulking agent, MBPSP has been made available from the shell of the T. fuscata. Having been utilized as a bulking agent in a pilot manufacture of pyrimethamine and pyridoxine hydrochloride tablets adopting the wet granulation technique in comparison with a commercial product, DCP. It was noted that MBPSP will be preferable in the formulation of pyrimethamine tablet than DCP. It was also recorded that neither MBPSP nor DCP was suitable in the formulation of pyridoxine hydrochloride tablets since up to the USP specified amount could not be released from their tablets after the maximum period of dissolution studies.

\section{Acknowledgment}

The authors acknowledge the immense assistance of Juhel Nigeria Limited in providing the pure samples of pyrimethamine and pyridoxine hydrochloride used in this study.

\section{Conflict of interest}

There is no conflict of interest concerning this study.

Excipient. Journal of Pharmaceutical and Allied Sciences, 2017; 14(1):2417-2429.

11. Ugoeze K. C., Udeala O. K. Application of Periwinkle Shell Bio-ash (Ugoeze-bio-ash) as CO2 Donor in the Formulation of an Effervescent Low Dose Aspirin Tablet. American Journal of Biomedical Science and Engineering, 2015; 1(5): 63-70.

12. British Pharmacopeia, Her Majesty's Stationery Office, London, 1998.

13. Shangraw R.F. Direct Compression Tabletting, Encyclopaedia of Pharmaceutical Technology, Vol.4, Marcel Dekker, U.S.A., 2nd ed., 1988; pp. 85-160.

14. Shangraw R.F. Compressed tablets by direct compression granulation in: Pharmaceutical Dosage Forms: Tablets, Vol.1, Marcel Dekker, U.S.A., 2nd ed., 1989; p. 195-246.

15. Setn B.B; Bandelin F.J. and Shangraw, R.F. Tablets in: Pharmaceutical Dosage Forms, Vol. I; Liebermann, H. and Lachman, L. (eds.), Marcel Dekker Inc, New York, 1980; p. 110 .

16. Marks A.M. \& Sciarra J.J. Effects of size and other physical properties of granules and their corresponding tablets, J. Pharm. Sci. 1968; 57: 497.

17. Parrot, E.L. Pharmaceutical Technology; Fundamental Pharmaceutics, Burges Pub. Co., Minneapolis, 1970; pp. 1718,74 .

18. Lazarus J. and Lachman L. Experiences in development of directly compressible tablets containing potassium chloride, J. Pharm. Sci. 1966; 55:1121.

19. Rasenack N. and Muller B.W. Crystal habit and tableting behaviour, Int. J. Pharm. 2002; 244:45-57

20. Sherringtonn P.J.; Oliver R. Granulation: in: Encyclopaedia of Pharmaceutical Technology, Vol. 3, 2nd Edition, Edited by 
James Swarbrick and James C. Boylan, Marcel Dekker, Inc New York, 1981; pp. 2713-2731.

21. Ejiofor O; Esezobo S, Pilpel N. The plasto-elasticity and compressibility of coated powders and the tensile strength of their tablets, J. Pharm. Pharmac. 1986; 38(1):1-7.
22. The United States Pharmacopoeia, U.S.P, NF. The United States Pharmacopoeial Convention, Rockville, 2007. 